\title{
Functional Neurological Disorder Presenting as Stroke: A Narrative Review
}

\author{
Abdelnour $\mathrm{LH}^{1 *}$ and El-Nagi $\mathrm{F}^{2}$ \\ ${ }^{1}$ Department of Acute Medicine, UK \\ ${ }^{2}$ Department of Stroke Medicine, Fairfield General Hospital, Manchester, UK
}

\begin{abstract}
Functional neurological symptom disorder (FNSD) represents one of the disorders that are continuously being revised by the diagnostic and statistical manual of disease (DSM) due to the lack of certainty of some of its clinical characteristics. In the last $5^{\text {th }}$ edition (DSM5), 7 subtypes have been proposed, but not all of them potentially present as stroke mimics. Though both FNSD and stroke are common in clinical practice, the prevalence of functional stroke is not well-known. The diagnosis of FNSD does not rely on the mere absence of medical explanation, but on active demonstration of symptom incompatibility with a medical disorder. In this narrative review, we explore the literature on the prevalence of functional stroke, its clinical presentation and the validated clinical signs of incongruity, the risk factors and cultural differences of clinical presentation and differentiation of FNSD from malingering. We also review the role of neuroimaging in establishing the diagnosis as well as the evidence of thrombolysis safety and some of the psychosomatic models of disease.
\end{abstract}

Keywords: Hysteria; Conversion; Neuroimaging; Psychosomatic

\section{Introduction}

Many original papers and reviews addressed functional neurological disorder in general, but there is paucity of literature on functional stroke, though both FNSD and stroke are common in clinical practice. In this narrative review, we aim to review the literature of FNSD, focusing on stroke subtypes. We discuss some of the history of hysteria, modern diagnostic criteria and classification, clinical features of functional stroke and its risk factors and cultural differences and how to differentiate it from malingering. We review prevalence, misdiagnosis and safety of thrombolysis of functional stroke, as well as the role of neuroimaging in establishing the diagnosis. We discuss the neuropsychiatric dilemma and some psychosomatic models of disease and review literature on prognosis and follow up.

\section{Historical Overview}

There are more than two centuries of published literature on hysteria or its synonyms, but the history even dates to the ancient Greeks, who believed that this phenomenon originated from the female's womb, and hence the term "hysterus" [1]. In the $19^{\text {th }}$ century, hysteria was regarded as a neurological disorder that lacked any neuropathological explanation, until it was transformed by Sigmund Freud into a psychiatric condition [2]. The Greeks described the disorder as the wandering womb, which moves freely within a woman's body causing her a variety of spasmodic symptoms. However, Thomas Chambers in a lecture delivered at St. Mary's Hospital in Manchester in 1861 strongly refuted that theory, and described medical practitioners who believed in such superstitions as not being trustworthy [3]. His argument was that there are many women with uterine pathologies with no tendency towards hysteria, and that most women with hysteria have a healthy uterus. He saw a woman with hysteria who was born without a uterus. The term "functional" is not new. Buzzard used this term to describe symptoms of hysteria in a paper published in 1899 to differentiate it from insular sclerosis [4]. Other physicians used their own terms to describe hysteria:

"Mocking bird of nosology" - Johnson 1849 "That strange disease"Gowers 1885 "Temper disease" - Ogle 1870 "Nervous mimicry" - Paget 1873.

"A complex morbid condition of all the cerebral function" - Aitkin
"A multiplicity of morbid phenomena used to denote an abnormal nervous system and mind which enters into a great variety of affections".

-Flint.

"A complex morbid condition, the nature of which is impossible to speak definitely, that belongs to nervous disorders, but its exact seat cannot be localized, though the brain is probably most disturbed."

-Koberts

Mai and Briquet [5] linked hysteria with stress and environmental situations, and suggested that it involved affective areas of the brain in persons with premorbid hypersensitivity, while, a French neurologist, described it as a disease of a psychological and no clear physiological or morphological etiology. Jean Martin Charcot (1825-1893), one of the greatest neurologists of the $19^{\text {th }}$ century or even been the founder of neurology, initially believed that hysteria was a neurological disorder influenced by environmental factors, but later labeled it as a psychological disorder [6]. There was a debate on whether classical hysteria of the $19^{\text {th }}$ century has declined. Some researchers, who extensively studied the history of hysteria like Micale [7], believe that hysteria in its old classical description by the $19^{\text {th }}$ century neurologists and psychiatrists has gone. It got broken down to its constituent symptomatology, and then got reassembled and distributed under different branches of medicine [7]. Stone et al. [8] believes that this disappearance of hysteria is an illusion, as patients tend to seek help from neurologists who are less keen to see them, and hence, discharge them without referral to psychiatrists. He demonstrated this neurological disinterest by examining textbooks published in English between 1877 and 2005 and found that the proportion of neurology textbooks devoted to hysteria or other

*Corresponding author: Loay $\mathrm{H}$ Abdelnour, Department of Acute Medicine Pindefields General Hospital, Aberford Rd, Wakefield WF1 4DG, UK, Tel: 00447438212260; E-mail: loayhassan@gmail.com

Received October 23, 2017; Accepted November 21, 2017; Published November 28, 2017

Citation: Abdelnour LH, El-Nagi F (2017) Functional Neurological Disorder Presenting as Stroke: A Narrative Review. J Psychol Abnorm 6: 159. doi: 10.4172/2471-9900.1000159

Copyright: ( 2017 Abdelnour LH, et al. This is an open-access article distributed under the terms of the Creative Commons Attribution License, which permits unrestricted use, distribution, and reproduction in any medium, provided the original author and source are credited. 
individual functional symptoms was negatively correlated with time [8]. Therefore, it is not that hysteria is disappearing; it is lack of interest from neurologists and lack of exposure from psychiatrists, leading to both under-reporting it.

\section{Modern Definitions}

In the modern history of medicine many terms have been used by physicians to describe this disorder, both in clinical practice and in published research. Some of the different labels that have been used include: functional neurological disorder, conversion disorder, hysteria, somatoform disorder, psychosomatic disorder, neurotic disorder, psychoneurosis, abnormal illness behavior, psychogenic disorder, supratentorial disorder and medically-unexplained symptoms. The World Health Organization International Classification of Disease, $11^{\text {th }}$ edition (WHO ICD 11) defines functional neurological symptom disorder (FNSD) as: "Presence of involuntary symptoms of motor or sensory dysfunction that can be positively identified as being internally inconsistent (e.g. with a positive Hoover's sign or tremor entrainment test, or incongruent with recognized disease processes." The Diagnostic and Statistical Manual of Mental Disorders, fifth edition (DSM-5) set diagnostic criteria in 2016. In the new classification, conversion and functional neurological symptom disorder are used synonymously. The suggested criteria are shown on Figure 1.

The DSM-5 had four major changes from the $4^{\text {th }}$ text revision edition DSM-IV-TR:

1. The elimination of the need for an underlying psychological stressor, as this is absent in many patients.

2. Emphasis on the need for demonstration of positive clinical findings to support incompatibility of symptoms with disease, rather than relying on absence of medical findings alone.

3. Elimination of the need to rule out feigning or malingering as a requirement to make the diagnosis.

4. The criterion on the previous edition that required exclusion of medical disease was substituted with criterion $\mathrm{C}$ that requires the

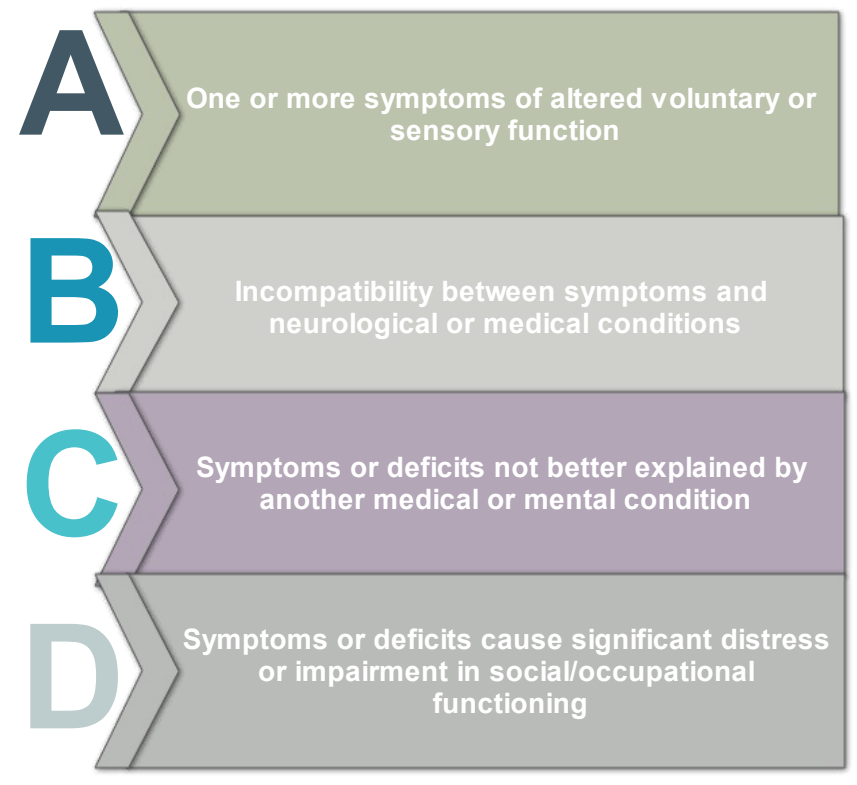

Figure 1: DSM-5 criteria for functional neurological disorder.

\begin{tabular}{|l|l|l|}
\hline 300.11 & $\begin{array}{l}\text { Conversion disorder (functional neurological symptom } \\
\text { disorder) }\end{array}$ \\
\hline & F44.4 & With abnormal movement \\
\hline F44.6 & With anaesthesia or sensory loss \\
\hline F44.5 & With attacks or seizures \\
\hline F44.7 & With mixed symptoms \\
\hline F44.6 & With special sensory symptoms \\
\hline F44.4 & With speech symptoms \\
\hline F44.4 & With swallowing symptoms \\
\hline F44.4 & With weakness/paralysis \\
\hline
\end{tabular}

Table 1: DSM-5 classifications of functional neurological disorder.

symptom is "not better explained by medical disease". This change is to allow for the possibility of presence of comorbid disease.

The same classification divides functional neurological disorders into 7 different categories as shown on (Table 1).

\section{The Neuropsychiatric Dilemma}

There has long been a disconnection between psychiatrists and neurologists regarding the care of patients with functional neurological disorders leading to these patients being a no-man's land. The main reasons are:

\section{Neurologists}

Lack of interest in 'non-organic' illness, more sick patients on neurology wards and pressure for beds, less understanding of biopsychosocial model of disease and fear of misdiagnosis.

\section{Psychiatrists}

Less understanding of neurologic symptoms, psychiatric wards less equipped for medical emergencies such as seizures, fear of misdiagnosis and fear of litigation. For some of these reasons the WHO ICD moved the disorder from under psychiatric section in the $10^{\text {th }}$ edition (ICD 10) to under neurology in the $11^{\text {th }}$ edition (ICD 11), mainly to encourage neurologists to take more responsibility and make a positive diagnosis of FNSD rather than just excluding neurologic disorder. Neurologists report they can make the diagnosis with confidence $[9,10]$. They mostly rely on inconsistency of symptoms, abnormal illness behaviour, type of symptom and psychological abnormality [10]. Most neurologists tend to avoid discussing psychological issues with patients when they seem resistant to it. Even when they suspect it, over $80 \%$ of neurologists would not talk about feigning with patients. Neurologists may order a battery of tests to satisfy patients that they have no physical basis for their symptoms and minimize their 'doctor shopping" [11]. However, performing investigation for anxious patients can be more anxiogenic than anxiolytic, as was shown by a controlled study of patients with chronic daily headache who were offered magnetic resonance imaging (MRI) of their head. Though they were less worried at 3 months from their scan, this was not sustained one year after [12]. Neurologists may endorse psychological models for conversion, but would still have limited understanding of their psychological basis [2].

Many of them would still not be able to separate it from feigning. They may feel it is not as easy as it says on the psychiatric manual, but many feels that distinction is not important [13]. In a questionnaire survey of 168 neurologists in the UK, $60 \%$ of neurologists would refer patients who are deemed to have no physical explanation of their disease back to the original referrer. These would more often be psychologists and physiotherapists, and less regularly (one in 10) would they be referred to psychiatrists, while psychiatrists feel that $70 \%$ of such patients would benefit from psychiatric assessment [14]. More 
popular terms or diagnostic labels used by neurologists to describe these patients are "functional, psychogenic and hysteria", while terms such as "neurotic, malingering and supratentorial" are less popular and used informally [14]. Use of the term "psychogenic" was strongly linked with term "hysteria". The term "functional" used by neurologists is largely confined to pseudo-seizures, anxiety neurosis and Munchausen's syndrome. Neurologists often find these patients somewhat or very difficult to help, compared to their other neurological patients [15].

\section{Psychosomatic Models of Disease}

Despite the interest of researchers in the relationship between psychological factors and disease, there is ongoing difficulty in having an ideal disease model to encompass the so called "psychosomatic disorders"; where physical symptoms have no objective clear medical explanation. The biomedical model, illustrated on Figure 2, has long been the one adopted by many physicians and even taught at medical schools, and is even the most dominant in research [16]. In this model, biological predisposition, in the presence of environmental factors or insults, results in disease. It defines disease as a verifiable evidence of a pathological state, evidenced by medical investigations. Hence, this model does not recognise illness, which is the patient's own perception of health. Though symptoms matter to patients, even though they have no "medical" explanation, this model does not acknowledge this fact, and results in physicians either abandoning these patients or feel helpless towards them. Furthermore, the substantial number of patients who attend hospitals and have no medical explanation, at least for all their symptoms, makes this model limited in addressing this problem. There are many issues that would limit the application of this model: There is evidence that psychosocial factors could have the same impact on cardiovascular morbidity as traditional risk factors such as high blood pressure and high cholesterol [17]. Psychosocial factors may influence success of most biological treatments (the placebo effect) [18]. Under certain circumstances, psychological factors could result in disease, which may be influenced by biomedical alterations [19]. The biopsychosocial model, on the other hand, acknowledges psychological factors in that disease can result from both biologic and psychologic predisposition, and that psychosocial modifiers could attenuate the outcome [20]. Based on this model, as on Figure 3, three factors would influence the development of disease or illness: biological (such as age, gender, genetics), psychological (such as mental and emotional health), and sociological (such as interpersonal relationships) [21]. This model, proposed by Engel, gives a better explanation of causation of non-communicable diseases, by giving similar emphasis of both biochemical and psychosocial correlates. This model has the added value of addressing life-style factors that are proved to influence the development of cardiovascular disease in type 2 diabetic patients [22]. A randomised controlled trial showed that biopsychosocial therapy achieves better results in patients with subacute low back pain compared

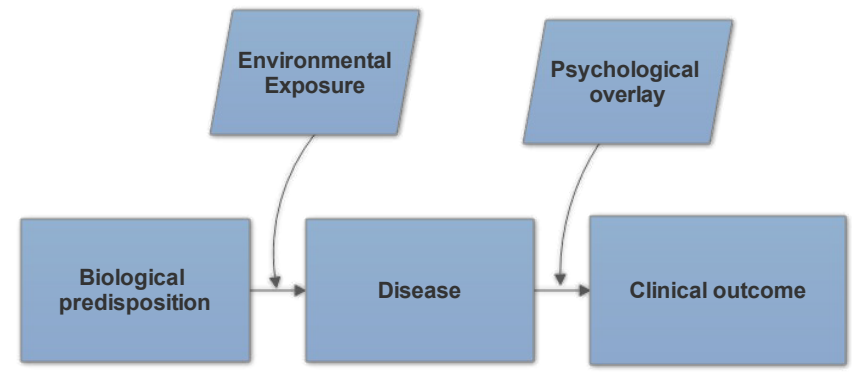

Figure 2: Biomedical model of disease.

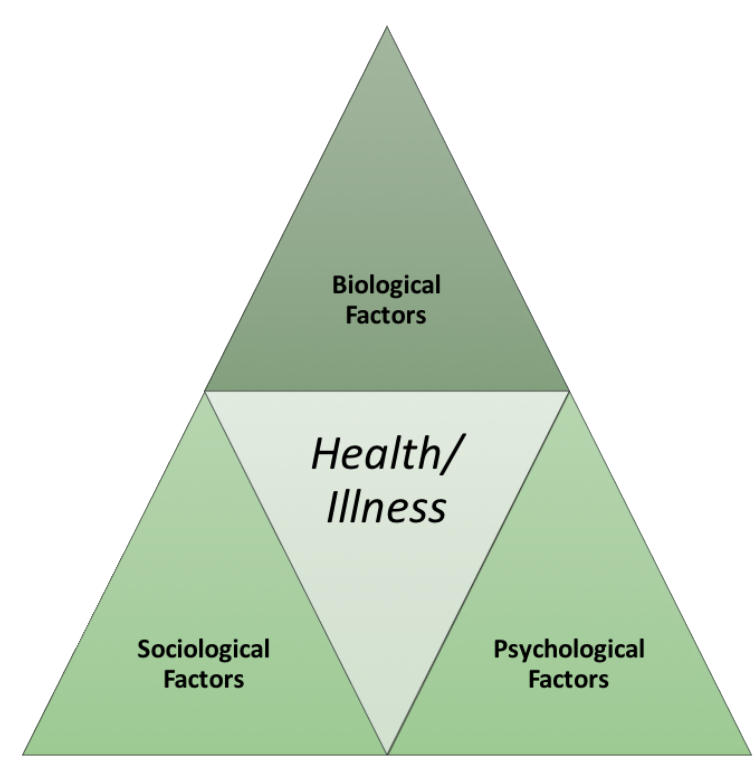

Figure 3: Biopsychosocial model of disease.

to conventional biomedical therapy especially in terms of functional status and work performance [23]. However, despite this clear evidence to support the biopsychosocial model, physicians feel uncomfortable in adopting it, mostly because of lack of sufficient training [24]. The biomedical model, with all its limitations, remains the most dominant in medical training in the United States [25] (Figures 1 and 2).

\section{Clinical Examination}

The DSM-5 criteria make it clear that diagnosis is not based on just excluding neurologic disease, but on clinical examination to demonstrate 'positive signs" to confirm or support the diagnosis of FNSD. This obviously falls on the shoulders of the neurologist. Several positive signs have been invented and even validated in recent years. A pilot study by Daum et al. [26] identified 6 positive signs as highly reliable and specific for conversion disorder, while another 13 signs could be considered as reliable and a further 6 suggestive of conversion disorder.

\section{Signs Supporting Functional Weakness of the Lower Limb}

\section{Give-way weakness (collapsing weakness)}

The patient initially displays reasonable power when his/her "paralyzed" limb is tested and then suddenly gives way and collapses when resistance is applied, even with a light touch [27]. The test has been validated in 2 studies with a pooled moderate sensitivity of $63 \%$ and a specificity of $97 \%$ [28]. False positive results can result from pain in the relevant joint, or from patients' poor understanding of instructions [27]. The sign is also seen in patients with acute stroke [29].

\section{Co-contraction}

When an agonist muscle group is tested against resistance, the examiner feels simultaneous contraction of the antagonist muscle group. This sign has a $100 \%$ specificity to conversion disorder, but with a low sensitivity of $17-30[26,30]$.

\section{Hoover's sign}

First described by Hoover in 1908 [31], this sign has been well- 
validated in clinical trials. It is usually performed to test for functional weakness of the lower limb, though it has also been described for upper limb weakness [26,32-34]. In normal individuals, voluntary flexion of a hip leads to involuntary extension of the contralateral hip because of crossed extensor reflex that facilitates normal walking. In a patient with functional weakness, when the examiner asks him/her to flex the "good hip" against resistance, the patient involuntarily extends the "allegedly weak" leg. Overall pooled sensitivity is $94 \%$ and specificity is $99 \%$ [28]. One controlled blinded inter-observer study reveals a sensitivity of $76 \%$ and specificity of $100 \%$. However, a false-positive result may result from hip pain, cortical neglect, or a splinting effect in normal subjects [27].

\section{Abductor sign}

The examiner asks the patient to abduct each leg against resistance, whilst feeling for movement of the opposite leg. In healthy individuals, the sound leg shows opposite movement, i.e., a hyper-adduction, to the weak leg. In patients with functional weakness this opposing movement is absent, and the sound leg remains static. This sign has been validated in only one study of 16 patients with functional paresis and a control of 17 patients with organic weakness, and showed a $100 \%$ sensitivity and specificity [34]. However, the study was not blinded, and with no interobserver reliability.

\section{Signs Supporting Functional Weakness of the Upper Limb}

\section{Drift without pronation}

In patients with upper motor neuron paralysis of the upper limb, when arm stabilization test is performed with the arms outstretched in full supination (palms facing upwards), the weak arm drifts downwards with mild elbow flexion, a pronator movement and passive abduction of the little fingers. Babinski [35] was the first to describe absent pronator drift as a sign of hysterical paralysis. The sign was prospectively validated in 26 patients with conversion disorder and 28 control patients with organic upper limb weakness and showed a sensitivity of $100 \%$ and a specificity of $93 \%$ [36]. The study was not blinded, and the results could have been overestimated if the same sign was used for the diagnosis. For this reason, the authors strictly used the DSM-IV criteria for selecting patients, rather than using the sign itself.

\section{Hoover's sign of the upper limb [31]}

As originally described by Hoover to detect malingering and functional paresis of the lower limb, this sign has been less wellvalidated for upper limb paralysis. One study performed to test for functional upper limb weakness with synkinetic finger abduction, used Hoover's sign as a control [31]. Ziv et al [37] performed Hoover's sign on both upper and lower limbs and obtained similar results. The test is performed by flexing the sound outstretched arm against resistance. This result in involuntary extension of the allegedly weak arm that fails to voluntarily extend.

\section{Abduction finger sign}

Abduction of fingers of one hand against resistance induces synkinetic finger abduction on the contralateral sound hand in healthy subjects, but not in patients with organic arm weakness. In patients with functional weakness, however, the test induces abduction synkinesia in the affected hand, with $100 \%$ sensitivity and specificity [33].

\section{Monrad-Krohn's test}

A less well-validated test, this sign was described by Monrad Krohn, a Norwegian neurologist in 1922, showing that weak contraction of the latissimus dorsi muscle against resistance of the horizontally extended arm in hysterical patients disappears when patients are asked to cough [38].

\section{Sternocleidomastoid muscle test}

Weakness of sternocleidomastoid muscle is tested by asking the patient to turn the head to the left and to the right and resist the examiner's attempt to bring it back to the midline. It is rare in organic disease, as the muscle is bilaterally innervated, and was seen in 24 out of $30(80 \%)$ patients with functional hemiparesis compared to only 3 out of $37(11 \%)$ patients with stroke $[39,40]$.

\section{Pseudo-waxy flexibility}

In both hysterical and hypnotized patients, keeping the weak arm outstretched might cause it to maintain position and inability to drop it down, a phenomenon not seen in organic paralysis [41].

\section{Signs Supporting Functional Sensory Symptoms}

\section{Splitting of the midline}

Loss of sensation on one side of the body including head, trunk and limbs is regarded as a feature of functional illness as the demarcation of sensory loss in the trunk is not usually at the midline, owing to the overlapping innervation from contralateral intercostal nerves. It has been validated in 3 studies, revealing a very low sensitivity of 18 $26 \%$, but with a specificity of $85-98 \%$ [41-44]. Organic disease such as thalamic stroke can result in midline splitting of sensation. This was demonstrated in subjects with hysterical hemi sensory loss with single photon emission computerized tomography (SPECT), revealing a decrease in cerebral blood flow in the contralateral thalamus and basal ganglia, which resolves after recovery [45].

\section{Splitting of vibration sense}

When a tuning fork is placed on one side of a single symmetrical or midline bone such as the sternum or the frontal bone, one would expect the vibration to be felt equally as it is bone-conducted. Splitting of this vibration sense means failure of the patient to feel it equally when it is placed on either side of the bone. Though the sign was elicited on $19 / 20$ patients with conversion disorder (95\% sensitivity), it was also elicited on $69 / 80$ patients with organic disease (14\% specificity), limiting the usefulness of this sign. In another case control study, the sign was positive in $39 \%$ of patients with functional weakness and $11 \%$ of patients with weakness from neurological disease, with no statistical comparison $[42,43]$.

\section{Other General Signs}

\section{La belle indifference}

This feature simply means that the patients are not bothered by their symptoms, and might even appear cheerful. It has been thought to be a sign of conversion disorder, but this is not the case. A systematic review of 11 studies reveals that this sign is present in $21 \%$ of patients with functional neurological disorder, and in $29 \%$ of patients with organic disease [46]. Most studies were not blinded and did not even give a clear description of what is meant by the phenomenon. Patients with organic disease might make efforts to appear cheerful, or it might simply be a feature of malingering, as the symptoms are deliberately made up by the patient [47].

\section{Differentiating conversion from malingering}

There is not a single clinical test or sign that would differentiate CD 
from feigning or malingering. All the signs were validated to separate inorganic from organic neurological disorder, but none are useful to separate conversion from malingering (strength of recommendation C, small lower-quality case-control studies) [48]. However, many neuropsychological tests have been proposed and validated for detection and correct diagnosis of malingering. Larrabee used 5 neuropsychological tests including Benton Visual Form Discrimination, Finger tapping, Reliable Digit Span, Wisconsin Card Sorting Failureto-Maintain Set and Lees-Haley Fake Bad Scale in 26 subjects with definite malingered neurocognitive dysfunction (MND) identified with significantly worse-than-chance performance on the Portland Digit Recognition Test (PDRT), and in 31 subjects with moderate to severe closed head injury [49]. Pair-wise combinations and cross-validation yielded a sensitivity of $87.8 \%$ and a specificity of $91.6 \%$ in correctly identifying malingering. The Halstead-Reitan Battery (HRB) is another neuropsychological test that has been validated in many studies to separate malingering patients from non-litigating head trauma patients and normal volunteers. Malingering patients perform more poorly on speech sounds perception, sensory suppressions, finger agnosia and Seashore Rhythm tests [50-52].

The Minnesota Multiphasic Personality Inventory-2 (MMPI-2) is the most widely used psychometric tests in adult psychopathology research, including malingering. The detection strategy of MMPI2 feigning indexes is the use of "rare symptoms", which are atypical symptoms or characteristics not commonly endorsed by the general population [53,54]. These feigning indexes include: $\mathrm{F}$ (Infrequency), $\mathrm{F}_{\mathrm{b}}$ (Back Infrequency) and $F_{p}$ (Infrequency-Psychopathology). Another important strategy in MMPI-2 is "erroneous subtypes" of Gough's Dissimulation Scale (D indexes) including: $\mathrm{D}_{\mathrm{s}}$ (Dissimulation) and $\mathrm{D}_{\mathrm{sr}}$ (Dissimulation - Revised). A third strategy is comparison of "obvious and subtle symptoms". A meta-analysis by Rogers et al. [55] of 62 MMPI-2 feigning and 11 MMPI-2 diagnostic studies suggests that $F_{p}$, though yielding a slightly lower effect size than $F$, is the most effective across diagnostic groups, and is more discriminant of feigning from genuine disorders. On the other hand, F produces a higher effect size, but is normative; i.e., only measures divergence from normality, but is not discriminant of feigning. The data questions the usefulness of $\mathrm{F}_{\mathrm{b}}$, as it is both normative and subjected to false- positives. Moreover, of the erroneous stereotypes strategy, $\mathrm{D}_{\mathrm{s}}$ are particularly useful, with consistent cut scores and low false-positive risk. The meta-analysis recommends combining different models of scales with specific strategies. The DSM-IV-TR defines malingering as: "intentional production of false or grossly exaggerated physical or psychological symptoms, motivated by external incentives" [56]. In neither DSM-IVTR nor the preceding edition was malingering regarded as a psychiatric condition, and remained as a V-code, which means it is not a diagnosis, and hence not a mental disorder [56].

\section{Role of Neuroimaging}

Criterion C of the DSM-5 definition of conversion disorder implies that symptoms are not better explained by a medical or mental disorder. This might necessitate performing neuroimaging to rule out other organic neurologic disorder such as stroke (negative diagnostic marker). But structural neuroimaging offers little information towards a positive diagnosis of FND, as opposed to functional neuroimaging.

\section{Structural neuroimaging}

Structural neuroimaging such as computed tomography (CT) and magnetic resonance imaging are performed to confirm evidence of ischemic/haemorrhagic stroke or other structural brain pathology in patients presenting with stroke symptoms. But these tests can be truly negative (stroke mimics) or falsely negative (neuroimagingnegative cerebral ischemia). The sensitivity of various modalities of neuroimaging has been reported in many studies. The lessons obtained from these studies are as follows:

MRI is more sensitive than CT in detecting acute ischemic stroke in the first $12 \mathrm{~h}$ of onset $[57,58]$. MRI has a better sensitivity than CT for lacunar infarcts [57]. CT has a low sensitivity in the first $3 \mathrm{~h}$ of onset, and it is only reliable for detecting cortical anterior circulation infarcts [57]. CT is only slightly superior to MRI in detecting haemorrhage (intracerebral or subarachnoid) in the acute phase, but MRI has more specificity in the later stages, though some studies even report comparable sensitivity of both modalities in the acute setting $[59,60]$. Diffusion-weighted imaging (DWI) is the only MRI modality that is sensitive to detect early ischemic parenchymal injury within the first $3 \mathrm{~h}[61,62]$. Despite the high sensitivity of MRI for acute ischemic stroke there is a false negative rate of 17 to $27 \%$ (for overall and early detection, respectively), compared to 84 to $88 \%$ for CT (for overall and early detection) [63]. DWI is more likely to be negative in stroke in early imaging (first 3 h), posterior stroke and small infarcts. Chalela et al. [63] reported an overall MRI sensitivity of $83 \%$ for detecting acute stroke compared to a CT sensitivity of $26 \%$. Within the first $3 \mathrm{~h}$ of onset, MRI sensitivity was $46 \%$ and CT sensitivity was $7 \%$. There is little data to support positive structural neuroimaging findings in conversion disorder. T1weighted MRI shows larger volumes in the left supplementary motor area, right superior temporal gyrus and dorsomedial prefrontal cortex of children and adolescents with conversion disorder [64]. These areas are believed to play a role in emotion processing. Whole brain MRI and Voxel-based morphometry (VBM) analysis show evidence of cortical atrophy in the right hemisphere and bilateral cerebella in patients with psychogenic non-epileptic seizures [65]. The same neuroimaging technique shows increased cortical thickness and grey matter volume in the premotor cortex bilaterally in patients with functional hemiparesis [66]. A structural MRI study in 10 women with conversion disorder with a healthy control reveals a normal whole brain volume and grey and white matter, but shows smaller bilateral basal ganglia (caudate and lentiform nuclei) and right thalamus in patients with CD [67-70].

\section{Functional neuroimaging}

Functional neuroimaging on the other hand gives promising directions towards understanding the pathophysiology of FND. Neuroimaging techniques that showed evidence of consistent features in conversion disorder are functional magnetic resonance imaging (fMRI), single photon emission computed tomography (SPECT) and positron emission tomography (PET). Most of studies that used these neuroimaging techniques had small number of participants (1 to 12). Hassa [68] demonstrated that simultaneous stimulation of emotional and motor networks by application of an fMRI paradigm to a group of patients with conversion disorder and a matched control results in hyper-activation of the left amygdala in the conversion disorder group. This occurs only during simultaneous negative emotional stimulation and passive movement of the affected hand. This gives evidence that patients with FND have altered emotional processing, as amygdala has been shown to be one of the brain structures that play a major role in emotional processing [71], as well as being linked to implicit integration of affect and drive [72]. fMRI was also used to demonstrate evidence that the cerebellum plays a role in freezing responses to aversive events, and that the cerebellum-limbic network is important for emotional processing [71]. 8 Patients with conversion disorder were assessed with a within-subject fMRI block, both during conversion and voluntaryinduced tremor. There was evidence of both temporoparietal junction (TPJ) hypoactivity and lower functional connectivity with sensorimotor 
and limbic regions [73]. Many fMRI studies show multiple neural correlates in patients with conversion disorder with no consistent findings, but the proposed theories are generally based on excessive inhibition and failure of activation of normal movement [74]. SPECT shows decreased perfusion in the left temporal and parietal regions in 5 patients with astasia-abasia (a gait abnormality with inability to stand or walk in the absence of other neurological signs) [75]. The same neuroimaging technique shows decreased cerebral blood flow in the contralateral thalamus and basal ganglia in 7 patients with hysterical sensorimotor loss, resolving after recovery [76]. The first study using PET scan was by Marshall in 1997 in a woman with long- standing left-sided functional paralysis. Brain activity was recorded during attempted movement of both the "paralyzed" and the good leg. Both attempted movements resulted in activation of motor and premotor cortex, but attempted movement of the weak leg also resulted in significant activation of right orbito-frontal and right anterior cingulate cortex, with failure of activation of the right primary motor cortex [77].

Another PET study in 3 men with hysterical arm weakness (2 left and 1 right) and 3 control feigners using a joystick task of the affected limb showed hypoactivity of dorso-lateral prefrontal cortex (DLPFC) during movement (but not at rest) in hysterical patients, while feigners had hypoactivity of the right frontal cortex, irrespective of their side of feigned weakness [78]. There are a few studies using PET scanning in hypnotically-induced paralysis. A single case study by Halligan et al. [79] in a 25 year old right-handed man, scoring positive on the Harvard group scale of hypnotic susceptibility, using hypnotic suggestion for left leg paralysis shows activation of the right anterior cingulate and right medial orbito-frontal cortex, similar to Marshall et al.s study [77] above, suggesting that hysteria and hypnosis possibly share similar neurophysiological correlates. Another study in 12 normal subjects used a within-subject design comparing brain activation on the same PET scanning session during both hypnotic suggestion and intentional simulation (feigning) of left leg paralysis [80]. During subjectively-experienced (hypnotically-induced) paralysis, that was a relative increase in activation in the right orbit-frontal cortex, right cerebellum and left putamen and thalamus (but not the right anterior cingulate cortex), while feigned paralysis was associated with relative increased activation in the left ventro-lateral prefrontal cortex. This study suggests that feigned paralysis has a different neural basis than subjectively experienced paralysis (including conversion).

\section{Prevalence}

\section{Outpatient setting}

In a large prospective multi-centre cohort (The Scottish Neurological Symptoms Study) of 3781 patients attending primary neurology clinics in Scotland and the UK, 30\% had symptoms "somewhat" or "not at all" explained by disease [81]. $16 \%$ of all patients had a diagnosis of psychological or functional disorder. Another Australian prospective cohort by Ahmad et al, including 884 patients attending outpatient neurology service, $15 \%$ had functional neurological disorder as their final diagnosis, after been followed up for a period of 17 months [82]. In one county hospital in the United States, the rate of hysterical neurosis was reported to be 22 cases per 100,000/year during the period between 1960-1969 [83]. Jankovic [84] reported a prevalence of psychogenic movement disorders of 5.3\%. Fink examined 198 consecutive new neurology inpatients and outpatients for somatoform disorders by using the Schedules for Clinical Assessment in Neuropsychiatry.

$61 \%$ had at least one medically unexplained symptom and $34.9 \%$ fulfilled the diagnostic criteria for an ICD-10 somatoform disorder [85]. An observational study in a Dutch population, consisting of self- assessment questionnaires, 35\% were considered to suffer from unexplained symptoms, with young age and female gender being the most common predictors [86]. A publication by Perkin [87] from Charing Cross Hospital in London reported that out of 7836 new outpatient referrals to a neurology clinic, $3.8 \%$ had a diagnosis of hysteria or conversion, with additional $1.8 \%$ having post-traumatic syndrome. The prevalence of medically unexplained symptoms across all specialties might even be higher as was shown on a South London survey in 2000 , where $52 \%$ of patients attending all outpatient clinics fulfilled the criteria for medically-unexplained symptoms, with the highest frequency (66\%) seen in gynaecology clinics [88].

\section{Inpatient setting}

An audit of resource use in patients with non-organic disorders admitted to a UK neurology unit in Oxford showed that out of 693 admissions to a general neurology ward, 48 (7\%) were non-organic, $9(2 \%)$ were uncertain and $3(<1 \%)$ were unknown [89]. The fraction of patients who had sensorimotor disturbance of the limbs was $29 \%$ of non-organic admissions (accounting for 1.45\%) of all admissions. Ewald et al. [90] investigated 100 consecutive patients newly admitted to a neurological department and found that $40 \%$ were somatizers. Among 4470 consecutive patients admitted to neurology wards "with typical neurological symptoms", 405 (9\%) had psychogenic rather than neurological disorder to explain their primary cause of admission [91] Motor symptoms were second to pain in order of frequency.

A study from King's College Hospital in London showed that out of 1165 patients admitted to the hyper acute stroke unit, $8.4 \%$ were functional mimics, with $63.3 \%$ being females [92]. Snyder and Strain [93] reported that the prevalence of somatoform disorder (based on DSM-III classification) detected during inpatient psychological consultations at Mount Sinai Hospital in New York between 1980 and 1987 was $1.8 \%$ and $2.6 \%$ during initial final consultations, respectively.

\section{Risk Factors for Conversion Disorder}

\section{Childhood trauma and physical and sexual abuse}

The relationship between conversion disorder and childhood trauma has been known for decades. Roelofs et al. [94] examined 54 children with $\mathrm{CD}$ matched with 50 controls with affective disorder using structured trauma interview as well as cognitive and somatoform questionnaires. $\mathrm{CD}$ children had a higher incidence of physical and sexual abuse, in addition to higher scores in paternal dysfunction from the mother and not the father. The same authors in another paper show that both the number and severity of life events in the year preceding the symptom onset are similar in patients with conversion and affective disorder [95]. However, these recent life events had a stronger relation with the severity of symptoms in conversion patients, especially events related to work and relationships. Another study shows that both physical and sexual abuse during childhood are observed in $32.4 \%$ of patients with non-epileptic seizures compared to $8.6 \%$ of patients with complex partial seizures [96]. Interestingly, a systematic review by Chen et al. [97] shows that sexual abuse is not significantly associated with a lifetime risk of somatoform disorders, though it has an association with an increased risk of anxiety, depression and post-traumatic stress disorder.

\section{Personal history of neurological disease}

Patients with a current or history of neurological disorder are more likely to suffer from conversion disorder. 10 To $60 \%$ of patients with psychogenic non-epileptic attacks also have epilepsy [98]. Mellers [99] report a rate of 10 to $30 \%$ of epilepsy in patients with dissociative 
seizures. $44 \%$ of patients with psychogenic seizures have evidence of co-existing neurological disorder on 5 years or more follow up post discharge [100].

\section{Family history of neurological disease}

Patients with conversion disorder may manifest the symptoms they see on a relative or a family member, the so-called "role model". $70 \%$ of parents of student aviators with conversion reactions had had a history of recurrent hospitalization or chronic serious illness [76]. Another Australian cohort of children with conversion disorder, however, shows recent family health issues in only 7\% [101].

\section{Clinical Presentation of Functional Stroke}

Though both stroke and functional neurological disorders are common in neurology practice, there is scant literature on the percentage of FND that presents under stroke services. The reasons for this paucity in data is not very clear but 2 explanations could be: Underreporting: either from neurologists offering patients with psychogenic symptoms a diagnosis of stroke without a substantial evidence, or from researchers omitting functional stroke percentage when they report stroke mimics [102].

Over-reporting: when neurologists strongly believe that patients have a psychological basis of their presentation, and not performing the essential diagnostic workup to rule out organic stroke. Three out of seven subtypes of the DSM-5 classification of FNSD would potentially present under stroke services. These are subtypes F44.4 "with speech disorder or swallowing symptoms", F44.4 "with motor symptoms", and F44.6 "with anesthesia or sensory loss". 98/1165 (8.4\%) Of patients admitted to stroke unit in King's College Hospital London had functional stroke. The commonest presentations were weakness and slurred speech [92]. An Australian cohort of 137 patients with FND shows sensory symptoms to be the commonest clinical presentation followed by limb weakness [82]. The diagnosis was more correlated with younger age, female gender and psychiatric comorbidity. The study was prospective, but performed in an outpatient setting and for all functional neurological disorders, not focusing on stroke mimics.

Analysis of 100 case series of hypoglossal nerve palsy showed hysteria as the cause in 6\% [103]. Among 821 patients admitted to a stroke unit, $13 \%$ had a misdiagnosis as stroke labelled as stroke mimics. $7.4 \%$ of those mimics were labeled as psychoneurosis [104]. Of 4470 consecutive neurological inpatients in Munich, Germany, 9\% had a psychogenic disorder. Pain was the commonest symptom, followed by motor symptoms, especially stance and gait disturbances and monoplegia [91]. A study of 143 children with suspected stroke reveals a 215 rate of stroke mimics [105]. 36.6\% and $23.3 \%$ of these mimics present with focal weakness and focal sensory change, respectively.

\section{Thrombolysis of Functional Neurological Disorder}

Psychogenic stroke may account for $10-28 \%$ of all stroke mimics [106-108]. A retrospective analysis of stroke registry data by Tsivgoulis et al. [109] revealed that 56 out of 539 cases who received intravenous thrombolysis had a misdiagnosis of stroke, of which $26.8 \%$ had conversion disorder. However, there was no case of intracranial haemorrhage and $96 \%$ of patients with stroke mimics were functionally independent upon discharge. A similar cohort by Chernyshev et al. [110] of 512 patients who had intravenous tissue plasminogen activator within $3 \mathrm{~h}$ of suspected ischemic stroke, $14 \%$ were stroke mimics, and had no instances of symptomatic intracranial haemorrhage. Conversion disorder was the third commonest mimic after seizures and complicated migraine. $87 \%$ of stroke mimics were independent at hospital discharge.
A large multicenter observational cohort of 5581 consecutive patients who received intravenous thrombolytic therapy, 100 Patients (1.8\%) were stroke mimics, $28 \%$ of who were psychogenic. Only 1 patient (1.0\%) of stroke mimics had a symptomatic intracranial haemorrhage [111]. An observational study that specifically examined the exclusion criteria for intravenous thrombolysis in patients with stroke mimics found that $13.4 \%$ of 842 patients presenting to an emergency department as stroke had stroke mimics and $4.4 \%$ of them had conversion disorder [112]. The two most frequent contraindications to thrombolytic therapy in stroke mimics were presentation outside of thrombolytic window and a National Institutes of Health Stroke Scale (NIHSS) being either immeasurable or small to warrant thrombolysis. The third much less common contraindication was rapidly improving symptoms. The only 2 patients who were eligible for thrombolysis with no contraindication did not receive it, either because they or their family refused it. In summary: patients with stroke mimics, including conversion disorder, most often would either not score high enough to warrant thrombolysis, or have contraindications to it. And when they receive thrombolytic therapy, they do not suffer from major adverse events, including intracranial haemorrhage. This helps to eliminate the physician's hassle when door to needle time is concerned, to give patients the benefit of doubt.

\section{Cultural Differences in Clinical Presentation}

There is evidence from published literature on some cultural and geographical variations in the predominant clinical presentations of conversion disorder. There is more prevalence of psudoseizures in Turkish than Dutch population [113]. The commonest presentation of conversion disorders in Turkish culture is pseudoseizures, followed by sensory symptoms in females and motor symptoms in males [114,115]. Other studies show that dizziness and fainting are the commonest manifestations of CD in Turkish population [116,117]. Taboas [118] reported a cohort of 15 Puerto-Rican patients (predominantly women) of multiple personality disorder (MPD), and $100 \%$ of them suffered from headaches and $93 \%$ had amnesia and depression. $73 \%$ of them suffered from sexual abuse and $60 \%$ from physical abuse during childhood. One study from the Netherlands by Boon and Draijer [119] shows that Dutch patients with multiple personality disorder have similar symptoms in both Europe and North America, but another study by Friedl and Draijer [120] suggests that the rate of dissociative disorders in Dutch patients is comparable to the rates reported in other European studies but lower than rates reported in North American studies. An Australian cohort of children with conversion disorder shows that their clinical presentation was complex, with disturbance of voluntary motor function being the most prevalent, followed by sensory symptoms [121]. These results replicate another Australian cohort of 52 children who were polysymptomatic, with gait disorder being the commonest presentation, followed by sensory symptoms, particularly pain [122]. There was a common notion that Chinese people are somatizers, and tend to present their emotions as physical symptoms, but Sing Lee, who extensively studies the Chinese culture, believes that the health care system in China is socioeconomically constrained and Chinese practitioners lack both time and expertise to provide psychotherapy, forcing patients to transform their psychiatric symptoms into physical ones, as a passport to physicians and pharmacotherapy [123]. Chinese psychiatrists have their own classification of mental health disorders called the Chinese Classification of Mental Disorders (CCMD), currently on its third version (CCMD-3). It bares more resemblance to the ICD-10 than to the DSM-1V [124]. Neurasthenia is a vague term used much more commonly in Chinese culture to cover psychoneurosis "physical symptoms with a psychiatric background", as a more sociallyacceptable and less stigmatized term to cover mental disorders [125]. 


\section{Prognosis and Follow Up}

A systematic review by Gelauff et al. [126], of studies reporting follow up of patients with functional/psychogenic motor symptoms for more than 6 months' duration shows great heterogeneity in study size, follow up duration and symptom outcome. 15 out of 24 studies included were retrospective. The clinical setting and data availability were also very variable. The mean follow up was 7.4 years. $10-90 \%$ of patients were "same" or "worse" at follow up (mean 39\%). Positive prognostic factors include: early diagnosis, short duration of symptoms and high level of satisfaction with care. Negative prognostic factors include: personality disorder and delayed diagnosis. The prognosis of functional paraplegia mimicking spinal cord injury is usually good when the duration of symptoms is short (acute), but tends to be less favourable when symptoms are longer-standing (months or years) [127-131]. Delargy et al. [132] successfully managed to get 6 patients with conversion paraplegia that were wheelchair-bound for a mean of 3 years to walk out of hospital with prolonged inpatient physical rehabilitation.

\section{Misdiagnosis}

Slater in 1965 [133] suggested that $61 \%$ of patients with hysteria would develop a neurological disorder after a 10 year follow up. However, the same work of Slater was reproduced by Crimlisk et al. [134] on 73 patients with medically unexplained motor symptoms and on 6 years follow up only $4 \%$ of them developed neurological disorders that would have explained their initial symptoms. A systematic review by Stone suggests that the rate of misdiagnosis of conversion disorder "hysteria" has fallen from $29 \%$ in the 1950 s to $4 \%$ in the 1970 s and remained steady since. This decline has not resulted from the advent of computed tomography, but from the improved quality of studies [134].

\section{Conclusion}

FNSD is a frequent presentation under stroke services, but facing both over and under-reporting. The DSM-5 criteria try to encourage neurologists to make a positive diagnosis by actively demonstrating clinical signs of symptom incongruity. There is currently no single test that positively supports this diagnosis, and it remains a clinical diagnosis. Many studies using functional neuroimaging were and are being conducted, but they only reveal neuro-correlates that are helpful to distinguish FNSD from feigning, rather than showing features specific to the disorder. Many patients get thrombolytic therapy, and the diagnosis is only made in retrospect. Though several risk factors have been linked to FNSD, its exact pathophysiology is still unclear, like other medical functional disorders.

\section{References}

1. Ford CV, Folks DG (1985) Conversion disorders: An overview. Psychosomatics 26: 371-383.

2. Kanaan R, Armstrong D, Barnes P, Wessely S (2009) In the psychiatrist's chair: How neurologists understand conversion disorder. Brain 132: 2889-2896.

3. Chambers TK (1861) Clinical lecture on hysteria: Given at St. Mary's hospital. Br Med J 2: 651.

4. Buzzard T (1899) Remarks on the differential diagnosis of insular sclerosis from hysteria. Br Med J 1: 1077.

5. Mai FM, Briquet MH (1981) Concept of hysteria: An historical perspective. BMC Nurs 26: 57-63.

6. Mace CJ (1992) Hysterical conversion. II: A critique Bjpsych 161: 378-389

7. Micale MS (1993) On the" disappearance" of hysteria: A study in the clinical deconstruction of a diagnosis. Isis 84: 496-526.

8. Stone J, Hewett R, Carson A, Warlow C, Sharpe M (2008) The 'disappearance' of hysteria: Historical mystery or illusion. JRSM 101: 12-18.
9. Stone J, La France WC, Brown R, Spiegel D, Levenson JL, et al. (2011) Conversion disorder: Current problems and potential solutions for DSM-5. Psychores 71: 369-376.

10. Kanaan RA, Armstrong D, Wessely SC (2011) Neurologists9 understanding and management of conversion disorder. BMJ 82: 961-966.

11. Espay AJ, Goldenhar LM, Voon V, Schrag A, Burton N, et al. (2009) Opinions and clinical practices related to diagnosing and managing patients with psychogenic movement disorders: An international survey of movement disorder society members. Mov Disord 24: 1366-1374.

12. Howard L, Wessely S, Leese M, Page L, McCrone P, et al. (2005) Are investigations anxiolytic or anxiogenic? A randomized controlled trial of neuroimaging to provide reassurance in chronic daily headache. BMJ 76: 1558 1564.

13. Kanaan R, Armstrong D, Barnes P, Wessely S (2009) In the psychiatrist's chair: How neurologists understand conversion disorder. Brain 132: 2889-2896.

14. Mace CJ, Trimble MR (1991) 'Hysteria', 'functional' or 'psychogenic'? A survey of British neurologists' preferences. JRSM 84: 471-475

15. Carson AJ, Stone J, Warlow C, Sharpe M (2004) Patients whom neurologists find difficult to help. BMJ 75: 1776-1778.

16. Drossman DA (1998) Gastrointestinal illness and the biopsychosocial model. Psychos Med 60: 258-267.

17. Rozanski A, Blumenthal JA, Kaplan J (1999) Impact of psychological factors on the pathogenesis of cardiovascular disease and implications for therapy. Circulation 99: 2192-2217.

18. Price DD, Finniss DG, Benedetti F (2008). A comprehensive review of the placebo effect: Recent advances and current thought. Annu Rev Psychol 59 . 565-590.

19. Engel GL (1980) The clinical application of the biopsychosocial model. Am J Psychiatry 137: 535-544.

20. Drossman DA (1998) Gastrointestinal illness and the biopsychosocial model. Psychos Med 60: 258-267.

21. Green BN, Johnson CD (2013) Establishing a theoretical basis for research in musculoskeletal epidemiology:A proposal for the use of biopsychosocial theory in investigations of back pain and smoking. J Chiropr Humanit 20: 1-8.

22. Chen L, Pei JH, Kuang J, Chen HM, Chen Z, et al.(2015) Effect of lifestyle intervention in patients with type 2 diabetes: A meta-analysis. Metabolism 64 338-347.

23. Moser EM, Stagnaro-Green A (2009) Teaching behavior change concepts and skills during the third-year medicine clerkship. Acad Med 84: 851-858.

24. Schiltenwolf M, Buchner M, Heindl B, von Reumont J, Müller A, et al. (2006) Comparison of a biopsychosocial therapy (BT) with a conventional biomedical therapy (MT) of subacute low back pain in the first episode of sick leave: A randomized controlled trial. Eur Spine J 15: 1083-1092.

25. McLean M, Gibbs TJ (2009) Learner-centered medical education: Improved learning or increased stress? Med Educ 22: 287

26. Daum C, Gheorghita F, Spatola M, Stojanova V, Medlin F, et al. (2014) Interobserver agreement and validity of bedside 'positive signs' for functional weakness, sensory and gait disorders in conversion disorder: A pilot study. $J$ Neurol Neurosurg Psychiatry 86: 425-430.

27. Stone J, Carson A, Sharpe M (2005) Functional symptoms and signs in neurology: Assessment and diagnosis. J Neurol Neurosurg Psychiatry 76: 2-12.

28. Daum C, Hubschmid M, Aybek S (2014) The value of 'positive' clinical signs for weakness, sensory and gait disorders in conversion disorder: A systematic and narrative review. J Neurol Neurosurg Psychiatry 85: 180-90.

29. Gould R, Miller BL, Goldberg MA, Benson DF (1986) The validity of hysterical signs and symptoms. J Nerv Ment Dis 174: 593-597.

30. Baker JH, Silver JR (1987) Hysterical paraplegia. BMJ 50: 375-382.

31. Hoover CF (1908) A new sign for the detection of malingering and functional paresis of the lower extremities. JAMA 51: 746-747.

32. McWhirter L, Stone J, Sandercock P, Whiteley W (2011) Hoover's sign for the diagnosis of functional weakness: A prospective unblinded cohort study in patients with suspected stroke. J Psychosom Res 71: 384-386.

33. Tinazzi M, Simonetto S, Franco L, Bhatia KP, Moretto G, et al. (2008) Abduction 
finger sign: A new sign to detect unilateral functional paralysis of the upper limb. Mov Disord 23: 2415-2419.

34. Sonoo M (2004) Abductor sign: A reliable new sign to detect unilateral nonorganic paresis of the lower limb. BMJ 75: 121-125.

35. Babinski J (1907) De la pronation de la main dans l'hémiplégie organique. Rev Neurol 15: 755.

36. Daum C, Aybek S (2013) Validity of the "Drift without pronation" sign in conversion disorder. BMC Neurol 13: 31

37. Ziv I, Djaldetti R, Zoldan Y, Avraham M, Melamed E (1998) Diagnosis of "nonorganic" limb paresis by a novel objective motor assessment: The quantitative Hoover's test. J Neurol 245: 797-802.

38. Tremolizzo L, Susani E, Riva MA, Cesana G, Ferrarese C, et al.(2014) Positive signs of functional weakness. J Neurol Sci 340: 13-18.

39. Goldstein DA (1990) Clinical methods: The history, physical, and laboratory examinations. Boston Butterworths.

40. Diukova GM, Stolajrova AV, Vein AM (2001) Sternocleidomastoid (SCM) muscle test in patients with hysterical and organic paresis. J Neurol Sci 187: 109.

41. Stone J, Zeman A, Sharpe M (2002) Functional weakness and sensory disturbance. BMJ 73: 241-245.

42. Stone J, Warlow C, Sharpe M (2010) The symptom of functional weakness: A controlled study of 107 patients. Brain 133: 1537-51.

43. Rolak LA (1998) Psychogenic sensory loss. J Nerv Ment Dis 176: 686-687.

44. Chabrol H, Peresson G, Clanet M (1995) Lack of specificity of the traditional criteria for conversion disorders. Eur Psychiatry 10: 317-319.

45. Vuilleumier P, Chicherio C, Assal F, Schwartz S, Slosman D, et al. (2001) Functional neuroanatomical correlates of hysterical sensorimotor loss. Brain 124: $1077-1090$

46. Stone J, Smyth R, Carson A, Warlow C, Sharpe M (2006) La belle in difference in conversion symptoms and hysteria. BJ Psych 188: 204-209.

47. Stone J, Carson A, Sharpe M (2005) Functional symptoms and signs in neurology: Assessment and diagnosis. BMJ 76: 2-12.

48. Greer S, Chambliss ML, Mackler L (2005) What physical exam techniques are useful to detect malingering? J Fam Pract 54: 711-722.

49. Larrabee GJ (2003) Detection of malingering using atypical performance patterns on standard neuropsychological tests. Clin Neuropsychol 17: 410-425.

50. Mittenberg W, Rotholc A, Russell E, Heilbronner R (1996) Identification of malingered head injury on the Halstead-Reitan Battery. Arch Clin Neuropsychol 11: 271-81.

51. Heaton RK, Smith HH, Lehman RA, Vogt AT (1978) Prospects for faking believable deficits on neuropsychological testing. J Consult Clin Psychol 46: 892.

52. Trueblood W, Schmidt M (1993) Malingering and other validity considerations in the neuropsychological evaluation of mild head injury. J Clin Exp Neuropsychol 15: $578-90$.

53. Camara WJ, Nathan JS, Puente AE ( 2000) Psychological test usage: Implications in professional psychology. Professional Psychology Research and Practice 31: 141-54.

54. Rogers R, Sewell KW, Martin MA, Vitacco MJ (2003) Detection of feigned mental disorders: A meta-analysis of the MMPI-2 and malingering. Assessment 10: 160-77.

55. Rogers R, Sewell KW, Martin MA, Vitacco MJ (2003) Detection of feigned mental disorders: A meta-analysis of the MMPI-2 and malingering. Assessment 10: 160-77.

56. Lebourgeois III HW (2007) Malingering: Key points in assessment. Psychiatr Times 24: 21.

57. Smajlović D, Sinanović O (2004) Sensitivity of the neuroimaging techniques in ischemic stroke. Med Arh 58: 282-284.

58. Saur D, Kucinski T, Grzyska U, Eckert B, Eggers C, et al. (2003) Sensitivity and interrater agreement of CT and diffusion-weighted MR imaging in hyperacute stroke. AJNR Am J Neuroradiol 24: 878-885

59. Fiebach JB, Schellinger PD, Gass A, Kucinski T, Siebler M, Villringer A et al. (2004) Stroke magnetic resonance imaging is accurate in hyperacute intracerebral hemorrhage. Stroke 35: 502-506.
60. Kidwell CS, Chalela JA, Saver JL, Starkman S, Hill MD, et al. (2004) Comparison of MRI and CT for detection of acute intracerebral hemorrhage. JAMA 292: 1823-1830.

61. Mitomi M, Kimura K, Aoki J, Iguchi Y (2014) Comparison of CT and DWI findings in ischemic stroke patients within 3 hours of onset. J Stroke Cerebrovasc Dis 23: $37-42$

62. Thomalla G, Rossbach P, Rosenkranz M, Siemonsen S, Krützelmann A, et al.(2009) Negative fluid attenuated inversion recovery imaging identifies acute ischemic stroke at $3 \mathrm{~h}$ or less. Ann Neurol 65: 724-732.

63. Chalela JA, Kidwell CS, Nentwich LM, Luby M, Butman JA, Demchuk AM, et al. (2007) Magnetic resonance imaging and computed tomography in emergency assessment of patients with suspected acute stroke: A prospective comparison. Lancet 369: 293-298.

64. Blakemore RL, Sinanaj I, Galli S, Aybek S, Vuilleumier P (2016) Aversive stimuli exacerbate defensive motor behaviour in motor conversion disorder. Neuropsychologia 93: 229-41.

65. Kozlowska K, Griffiths KR, Foster SL, Linton J, Williams LM, et al (2017) Grey matter abnormalities in children and adolescents with functional neurological symptom disorder. Neuroimage 15: 306-14.

66. Aybek S, Nicholson TR, Draganski B, Daly E, Murphy DG, David (2012) Grey matter changes in motor conversion disorder. J Neurol Neurosurg Psychiatry.

67. Atmaca M, Aydin A, Tezcan E, Poyraz AK, Kara B (2006) Volumetric investigation of brain regions in patients with conversion disorder. Prog Neuropsychopharmacol Biol Psychiatry 30: 708-713.

68. Hassa T, Sebastian A, Liepert J, Weiller C, Schmidt R, et al. (2017) Symptomspecific amygdala hyperactivity modulates motor control network in conversion disorder. Neuroimage 15: 143-50.

69. Richter-Levin G (2004) The amygdala, the hippocampus and emotional modulation of memory. Neuroscientist 10: 31-9.

70. Mega MS, Cummings JL, Salloway S, Malloy P (1997) The limbic system: an anatomic, phylogenetic and clinical perspective. J Neuropsychiatry Clin Neurosci 9: 315-330.

71. Blakemore RL, Sinanaj I, Galli S, Aybek S, Vuilleumier P (2016) Aversive stimuli exacerbate defensive motor behaviour in motor conversion disorder Neuropsychologia 93: 229-241.

72. Kozlowska K, Griffiths KR, Foster SL, Linton J, Williams LM, et al. (2017) Grey matter abnormalities in children and adolescents with functional neurological symptom disorder. Neuroimage 15: 306-314

73. Voon V, Gallea C, Hattori N, Bruno M, Ekanayake V, Hallett M (2010) The involuntary nature of conversion disorder. Neurology 74: 223-228.

74. Stone J, Zeman A, Simonotto E, Meyer M, Azuma R, et al. (2007) fMR in patients with motor conversion symptoms and controls with simulated weakness. Psychosom Med 69: 961-969.

75. Yazici KM, Kostakoglu L (1998) Cerebral blood flow changes in patients with conversion disorder. Psychiatry Res 83: 163-168.

76. Vuilleumier P, Chicherio C, Assal F, Schwartz S, Slosman D, et al. (2001) Functional neuroanatomical correlates of hysterical sensorimotor loss. Brain. 124: $1077-1090$

77. Marshall JC, Halligan PW, Fink GR, Wade DT, Frackowiak RS (1997) The functional anatomy of a hysterical paralysis. Cognition 64: B1-B8.

78. Spence SA, Crimlisk HL, Cope H, Ron MA, Grasby PM (2000) Discrete neurophysiological correlates in prefrontal cortex during hysterical and feigned disorder of movement. Lancet 355: 1243-1244.

79. Halligan PW, Athwal BS, Oakley DA, Frackowiak RS et al. (2000) Imaging hypnotic paralysis: Implications for conversion hysteria. Lancet 355: 986-987.

80. Ward NS, Oakley DA, Frackowiak RS, Halligan PW (2003) Differential brain activations during intentionally simulated and subjectively experienced paralysis. Cogn Neuropsychiatry 8: 295-312

81. Stone J, Carson A, Duncan R, Roberts R, Warlow C, et al. (2010) Who is referred to neurology clinics? The diagnoses made in 3781 new patients. Clin Neurol Neurosurg 112: 747-751.

82. Ahmad O, Ahmad KE (2016) Functional neurological disorders in outpatien practice: An Australian cohort. J Clin Neurosci 28: 93-96.

83. Stefansson JG, Messina JA, Meyerowitz S (1976) Hysterical neurosis 
conversion type: Clinical and epidemiological considerations. Acta Psychiatr Scand 53:119-138.

84. Jankovic J (2009) Treatment of hyperkinetic movement disorders. Lance Neurol 8: 844-856.

85. Fink P, Hansen MS, Søndergaard L (2005) Somatoform disorders among firsttime referrals to a neurology service. Psychosomatics 46: 540-548.

86. Snijders T, Leeuw FE, Klumpers UH, Kappelle LJ, Gijn JV (2004) Prevalence and predictors of unexplained neurological symptoms in an academic neurology outpatient clinic. J Neurol 251: 66-71.

87. Perkin GD (1989) An analysis of 7836 successive new outpatient referrals. J Neurol 52: 447-448.

88. Nimnuan C, Hotopf M, Wessely S (2001) Medically unexplained symptoms: An epidemiological study in seven specialities. J Psychosom Res 51: 361-367.

89. Parry AM, Murray B, Hart Y, Bass C (2006) Audit of resource use in patients with non-organic disorders admitted to a UK neurology unit. J Neurol 77: 1200-1201.

90. Ewald H, Rogne T, Ewald K, Fink P (1994) Somatization in patients newly admitted to a neurological department. Acta Psychiatr Scand 89: 174-179.

91. Lempert T, Dieterich M, Huppert D, Brandt T (1990) Psychogenic disorders in neurology: frequency and clinical spectrum. Acta Psychiatr Scand 82: 335-340.

92. Gargalas S, Weeks R, Khan NB, Shotbolt P, Simblett S, et al. (2017) Incidence and outcome of functional stroke mimics admitted to a hyperacute stroke unit. J Neurol Neurosurg Psychiatry 88: 2-6.

93. Snyder S, Strain JJ (1981) Somatoform disorders in the general hospita inpatient setting. Gen Hosp Psychiatry 1: 288-293.

94. Roelofs K, Keijsers GP, Hoogduin KA, Näring GW, Moene FC (2002) Childhood abuse in patients with conversion disorder. Am J Psychiatry 159: 1908-1913.

95. Roelofs K, Spinhoven P, Sandijck P, Moene FC, Hoogduin KA (2005) The impact of early trauma and recent life-events on symptom severity in patients with conversion disorder. J Nerv Ment Dis 193: 508-514.

96. Alper K, Devinsky O, Perrine K, Vazquez B, Luciano D (1993) Nonepileptic seizures and childhood sexual and physical abuse. Neurology 43: 1950.

97. Chen LP, Murad MH, Paras ML, Colbenson KM, Sattler AL, et al. (2010) Sexua abuse and lifetime diagnosis of psychiatric disorders: systematic review and meta-analysis. Mayo Clin Proc 85: 618-629.

98. Duncan R, Oto M, Martin E, Pelosi A (2006) Late onset psychogenic nonepileptic attacks. Neurology 66: 1644-1647.

99. Mellers JD (2005) The approach to patients with "non-epileptic seizures". Postgrad Med J 81: 498-504.

100. Krumholz A, Niedermeyer E (1983) Psychogenic seizures A clinical study with follow-up data. Neurology 33: 498.

101. Kozlowska K, Nunn KP, Rose D, Morris A, Ouvrier RA, et al. (2007) Conversion disorder in Australian pediatric practice. J Am Acad Child Adolesc Psychiatry 46: $68-75$.

102. Behrouz R, Benbadis SR (2014) Psychogenic pseudostroke. J Stroke Cerebrovasc Dis 23: 243-248.

103. Keane JR (1996) Twelfth-nerve palsy: Analysis of 100 cases. Arch Neurol 53: 561-566.

104. Norris JW, Hachinski VC (1982) Misdiagnosis of stroke. Lancet 319: 328-331.

105. Shellhaas RA, Smith SE, O'Tool E, Licht DJ, Ichord RN (2006) Mimics of childhood stroke: Characteristics of a prospective cohort. Pediatrics 118: 704709.

106. Harbison J, Hossain O, Jenkinson D, Davis J, Louw SJ, (2003) Diagnostic accuracy of stroke referrals from primary care, emergency room physicians and ambulance staff using the face arm speech test. Stroke 34: 71-76.

107. Chernyshev OY, Schild SM, Albright KC, Barreto A, Misra V, et al. (2010) Safety of tPA in stroke mimics and neuroimaging-negative cerebral ischemia. Neurology 74:1340-1345.

108.Zinkstok SM, Engelter ST, Gensicke H, Lyrer PA, Ringleb PA, et al. (2013) Safety of thrombolysis in stroke mimics. Stroke 44: 1080-1084.

109. Tsivgoulis G, Alexandrov AV, Chang J, Sharma VK, Hoover SL, et al. (2011)
Safety and outcomes of intravenous thrombolysis in stroke mimics. Stroke 42 1771-1774.

110. Chernyshev OY, Schild SM, Albright KC, Barreto A, Misra V, et al. (2010) Safety of tPA in stroke mimics and neuroimaging-negative cerebral ischemia. Neurology 74: 1340-1345

111. Zinkstok SM, Engelter ST, Gensicke H, Lyrer PA, Ringleb PA, et al. (2013) Safety of thrombolysis in stroke mimics. Stroke 44: 1080-1084.

112. Brunser AM, Illanes S, Lavados PM, Muñoz P, Cárcamo D, et al. (2013) Exclusion criteria for intravenous thrombolysis in stroke mimics: an observational study. J Stroke Cerebrovasc Dis 22: 1140-1145.

113. Sar V (2014) The scope of dissociative disorders: An international perspective. Psychiatr Clin North Am 29: 227-244.

114. Ercan ES, Varan A, Veznedaroğlu B (2003) Associated features of conversion disorder in Turkish adolescents. Pediatr Int 45: 150-155.

115. Tsar V, Kundakci T, Kiziltan E, Bakim B, Bozkurt O (2001) Differentiating dissociative disorders from other diagnostic groups through somatoform dissociation in Turkey. $\mathrm{J}$ Trauma Dissoc 1: 67-80.

116. Deveci A, Taskin O, Dinc G, Yilmaz H, Demet MM, et al. (2007) Prevalence of pseudoneurologic conversion disorder in an urban community in Manisa, Turkey. Soc Psychiatry Psychiatr Epidemiol 42: 857-864.

117. Sar V, Akyüz G, Dogan O, Öztü E (2009) The prevalence of conversion symptoms in women from a general Turkish population. Psychosomatics 50 50-58.

118. Taboas AM (1991) Multiple personality in Puerto Rico: Analysis of fifteen cases. Dissociation 4: 189-192.

119. Boon S, Draijer N (1993) Multiple personality disorder in the Netherlands. Am J Psychiatry 1: 489.

120. Friedl MC, Draijer N (2000) Dissociative disorders in Dutch psychiatric inpatients. Am J Psychiatry 157: 1012-1013.

121. Kozlowska K, Nunn KP, Rose D, Morris A, Ouvrier RA, et al. (2007) Conversion disorder in Australian pediatric practice. J Am Acad Child Adolesc Psychiatry 46: 68-75.

122. Grattan-Smith P, Fairley M, Procopis $P$ (1988) Clinical features of conversion disorder. Arch Dis Child 63: 408-414.

123. Lee S (1997) A Chinese perspective of somatoform disorders. J Psychosom Res 43: 115-119.

124. Lee S (1996) Cultures in psychiatric nosology: The CCMD-2-R and internationa classification of mental disorders. Cult Med Psychiatry 20: 421-472.

125. Kleinman A (1982) Neurasthenia and depression: A study of somatization and culture in China. Cult Med Psychiatry 6: 117-90.

126. Gelauff J, Stone J, Edwards M, Carson A (2013) The prognosis of functional (psychogenic) motor symptoms: A systematic review. J Neurol Neurosurg Psychiatry 85: 220-226

127. Dickson H, Cole A, Engel S, Jones RF (1984) Conversion reaction presenting as acute spinal cord injury. Med J Aust 141: 427-429.

128. Weingarden SI, Lynch CG (1984) Functional paralysis mimicking spinal cord injury resulting in admission to a spinal cord injury Centre. Arch Phys Med Rehabil 65: 145-147.

129. Williams RSM, Marsh H (1985) Simulated paraplegia: An occasional problem for the neurosurgeon. J Neurol 48: 826-831.

130. Hafeiz HB (1980) Hysterical conversion: A prognostic study. Br J Psychiatry 136: $548-551$.

131. Withrington RH, Parry CW (1985) Rehabilitation of conversion paralysis J Bone Joint Surg Br 67: 635-637.

132. Delargy MA, Peatfield RC, Burt AA (1986) Successful rehabilitation in conversion paralysis. Br Med J 292: 1730-1731.

133. Slater E (1965) Diagnosis of "hysteria". Br Med J 1: 1395-1399.

134. Crimlisk HL, Bhatia K, Cope H, David A, Marsden CD, et al. (1998) Slater revisited: 6 year follow up study of patients with medically unexplained motor symptoms. BMJ. 316: 582-586. 